\title{
The Fourth International Congress of Refrigeration.
}

THE fourth International Congress of Refrigeration was held in London in June last. The Congress was organised by a committee of the British Cold Storage and Ice Association, working in conjunction with the Institut International du Froid. This International Institute is an organisation in which each State, Dominion, or Colony, signatory to the International Convention, is represented by delegates appointed by the participant State in a number proportioned in accordance with the amount of annual subsidy, varying from 1000 to 12,000 francs. It is interesting to note that forty-eight countries have signed the International Convention.

The Institute devotes its energies to further the science of refrigeration; to encourage the study of the best solutions of questions relating to the conservation, the transit, and the distribution of perishable produce ; to the publication of all information relating to the world's frozen-food situation.

The study of the above-mentioned subjects is pursued by sixteen separate commissions. The function of the International Congresses is to coordinate and afford a common. meeting ground for the members of these commissions and to all interested in refrigeration.

The work of the London Congress was subdivided between seven sections dealing respectively with: I. Scientific Questions-Physics, Units, and Biology. 2. Refrigerating Materials-Machines, Insulating Materials and Testing. 3. General Applications of Refrigeration-Food, Agriculture, Ice, etc. 4. Refrigerated Transport-Railway and Steamship. 5 . Legislation. 6. Education and Propaganda. 7. General Economics and Statistics. Thus one section would embrace the subjects coming within the purview of a number of separate commissions.

The meetings of the Congress were well attended by those engaged in the practical side of refrigeration. The title "Congress of Refrigeration" failed to attract many physicists, although Section I had on its programme a fine series of papers from the Leyden Cryogenic Laboratory.

The character of the papers will be realised from the following titles selected at random: "Organisation of the Work of Commission No. I " (Kamerlingh Onnes). "Report on the Freezing Point Temperatures of Organic Substances suitable for Use as Reference Points for the Low Temperature Scale" (Jean Timmermans). "The Isotherms of Hydrogen, from $-217^{\circ}$ C. to $-240^{\circ}$ C." (J. C. Swallow). "Report on the X-ray Investigation of the Constitution in the Liquid and Solid States of Substances at Low Temperatures" (W. H. Keesom). "Low Temperature Investigations in the Service of Cosmical Physics" (L. Vegard).

The papers of a biological character submitted to Section I were rather disappointing, and it was evident that the majority of the contributors did not regard the Congress as the place to discuss purely scientific matters. It is a pity that this outlook should prevail, for it is obvious that an international congress which gathers under one roof the diverse interests concerned can exert an enormous influence on the progress of refrigeration on both the theoretical and the practical sides. Hence, on the purely biological side of the science of refrigeration there is but little which calls for comment, so far as the present Congress is concerned.

Some of the most interesting of the papers on the practical side were those dealing with the transport of refrigerated produce by land and sea and those on special applications of refrigeration. Of the papers dealing with the marine side, one might be mentioned "Special Methods of Construction of Ships and Refrigerating Appliances for Vessels employed on Long Voyages "(A. R. T. Woods).

As regards land transport, the paper on "The Influence of Refrigeration in the Preservation of Fruit with Special Reference to South African Export Varieties " (I. B. Pole-Evans and Edgar A. Griffiths) is noteworthy, as it records the results of experiments on special trucks carrying fruit a distance of rooo miles through semi-tropical heat.

The paper on "Temperature and Metabolic Balance in Living Plant Tissues " (F. Kidd and C. West) is a useful sketch of some recent work in America and Germany.

The work of the Insulation Sub-Committee of the Food Investigation Board was summarised in a paper of about eighty pages with the title "The Scientific Study of Heating Insulating Materials " (Sir Richard Glazebrook and E. Griffiths).

An interesting contribution on one of the special applications of refrigeration was that on "The Application of Refrigeration to the Ventilation of Mines" (F. A. Willcox and J. D. Farmer).

Mr. W. B. Hardy, director of the Food Investigation Board, gave an admirable sketch of what he considered to be the correct function of the Food Investigation Board and the work of a research station. He pointed out that of the problems which an industry presents, some are fundamental and farreaching, others special and local. He quoted two examples to illustrate what the Board conceived to be their special province of work. One was the problem of the freezing of beef and most white fish. Can these materials be so frozen as to recover their original state on thawing ? When beef is thawed after being frozen, its texture is impaired, and it drips a fluid rich in dissolved nutritive material. This is due to that separation of water from other constituents which is a common feature in the freezing of solutions. Is it possible so to modify the whole cycle of physical events compressed in freezing and thawing as to bring this separation of water under such control as will lie within the four corners of a possible commercial process? No answer is yet forthcoming, because the theory of the freezing of tissues is yet in its infancy. Animal tissues are colloidal structures, and of the effects of low temperatures on colloids little is known. This is a fundamental problem because its solution involves the whole theory of the freezing of tissues. If and when it is solved, and it may be years before that difficult end is attained, any feat of freezing should be possible, or, to be more exact, the possibilities and impossibilities of freezing as a mode of preserving animal or plant tissues should be capable of fairly exact delimitation.

The other problem put forward by Mr. Hardy was purely physical. The Board were consulted as to the following :

A certain store was cooled by a fan driving air over calcium chloride brine, the cold air being then supposed to circulate throughout the chamber. Meat stored there became discoloured and unpleasant to sight and touch. This was ascribed to putrefactive organisms - to bacteria, in short. The solution of the problem proved simple. Bacteria as the causa vera were readily ruled out. The wind from the fan produced an invisibly fine spray of brine which settled on the surface of the carcases, where the calcium chloride reacted with the red colouring matter hæmoglobin to produce methæmoglobin. The scientific interest up to this point is small, and the problem,

$$
\text { NO. } 2859 \text {, VOL. I I } 4 \text { ] }
$$


though of some practical interest, does not rise above the level of the ordinary works laboratory. A study of the air currents in the chamber, however, revealed the fact that the fan, though seemingly placed where it would circulate the whole body of enclosed air, did as a matter of fact merely puddle in its own neighbourhood, producing powerful vortices on the surface of the brine. This and many similar instances have convinced the Board that the principles which underlie the movement of air in a space partly occupied by solid masses, such as the cargo in a hold, or the carcases in a store, are not clear, and therefore they have arranged that this general fundamental inquiry shall be prosecuted at the National Physical Laboratory.

This example will serve to show how the particular leads to the general; but general solutions are not reached readily, and, therefore, if each particular problem is regarded only as the door to the general, the number of problems which can be undertaken by the small staff at the disposal of the Board is limited.
The papers on the practical engineering aspect of cold storage were so numerous, and the impression which the Congress left upon one was that the progress made on the purely technical side has been so considerable, that it threw into strong relief the inadequacy of our knowledge on the fundamental problems of biology.

A Congress such as the one under review, with its strong international backing, should have been the occasion for a frank review of the situation and for discussions on the fundamental problems with which the industry is faced. The proceedings of these successive congresses could be made to serve as definite landmarks in the history of the science of refrigeration by epitomising the advances made in the intervening years both in pure and applied science, in so far as they relate to the preservation of perishable food-stuffs, and by formulating the general plans of attack on the new problems.

EZER Griffiths.

\section{Mechanism of Cell Growth.}

$\mathrm{I}$ the higher plants, new cells are formed and new tissues arise by the activity of certain definitely localised and clearly characterised tissues, the meristems. In the Dicotyledon, these are found at the apex of root and shoot, that is, at either end of the growing axis; in addition, two continuous cylinders of meristem, the cork phellogen and vascular cambium, run lengthwise through the axis and contribute to its subsequent increase in girth. Within these meristems proceeds the construction of new protoplasm, with subsequent mitotic division" into new cells as nuclear and cytoplasmic substance accumulates. In such a plant, then, the fundamental metabolic synthesis inseparable from growth, with the subsequent multiplication of the cells of the embryonic tissue, can be visualised as proceeding in strictly localised regions, and the question as to the conditions which promote such growth and division can to some extent be investigated experimentally. Within recent years the meristems have been examined from this point of view. It is clear that if their investigation gives any information as to the condition favouring such a fundamental process as the growth and multiplication of embryonic cells, this information may have very general importance and illuminate a wide range of problems.

From this point of view, an article by Friedl Weber in Die Naturwissenschaften for April I8 is of exceptional interest, as it reviews the recent plant physiological approach to these problems from a wide angle and with a wealth of documentation (for citation to original papers referred to below, reference must be made to Weber's paper).

The best known contribution to the conditions governing meristem activity is Haberlandt's theory as to the circumstances which give rise to a new meristem when the plant is wounded and a cork phellogen arises as a result. In this case, cells that have differentiated, and ceased to grow, return again to the embryonic state, and Haberlandt traces this to the effect upon these cells of growth-promoting hormones released from the injured cells. Weber examines the view sympathetically, and has himself used it to explain the forcing of buds from their winter's rest by freezing, narcotics, and various other methods by the assumption that the efficacity of the treatment depends upon the release of such hormones as the result of " physiological wounds" within the bud. Schillings' experiments, however, in which stems of flax and hemp, bent so that they droop earthwards, grow vigorously in the region of the flexure, tell strongly against Haberlandt's view, as this stimulus to growth disappears, although the injury does not, when the shoot is supported in the erect position after bending. But the greatest disadvantage of Haberlandt's view is that it throws no light upon the normal meristematic activity of the uninjured plant.

From this point of view, therefore, Weber finds a wider significance in the views recently developed by Priestley and Woffenden. These investigators similarly start from an examination of wound cork, but the conclusions they reach that its formation depends upon, first, a blocking of the wounded surface, and then an accumulation of sap in the walls and intercellular spaces below this block, enable them by consistent use of the same developmental factors to give a causal explanation of the position of the normal cork phellogen clothing root and stem. Weber then proceeds to a discussion of the more general suggestion as to the conditions for activity of the intercalary meristems of the Dicotyledon recently advanced by Pearsall and Priestley. These authors have pointed out that these two cylinders of meristem appear to be functioning across two reverse gradients of hydrogen ion concentration, the vascular cambium lying between acid xylem within and relatively alkaline phloem without, whilst the cork phellogen has within it the cortex at about $\mathrm{P}_{\mathrm{H}} 6$, but outside it cells, the walls of which are bathed. in fatty acids with a reaction of $\mathrm{P}_{\mathrm{H}} 3$. Weber examines in the light of a wealth of relevant data the suggestion of Pearsall and Priestley that protoplasmic synthesis, and therefore meristem activity, takes place, across this gradient, at the iso-electric point of the cell proteins, the protoplasm at this reaction losing water to cells on either side which, being at other points on the hydrogen ion gradient, swell and vacuolate, withdrawing water from the meristem.

Weber points out that many other physico-chemical properties of the colloidal state of protoplasm are involved in addition to the power of absorbing water. and emphasises that the delicate equilibrium of these properties, which alone permits of protoplasmic synthesis and mitotic division, probably will only be maintained over a limited range of hydrogen-ion concentration. From this point of view, he reexamines Kühns' classical experiments upon nuclear and cell division in Amœba, and directs special attention to the experiments which, by micro-dissection or 